15 Di Bona GF, Sawin LL. Renal tubular site of action of felodipine. F Pharmacol Exp Ther 1984;223:420-4.

16 Bruun NE, Ibsen H, Skoot P, Toftdahl D, Giese J, Holstein-Rathlou NH. Lithium clearance and renal tubular sodium handling during acute and lon 13.

17 Petersen V, Hvidt S, Thomsen K, Schou M. Effect of prolonged thiazide treatment on renal lithium clearance. Br Med f 1974 ;iii: 143-5.

18 Cappuccio FP, Mark ND, MacGregor GA. Calcium angenis and sodium balance. Effect of changes in sodium intake and of the addition of a sodium balance. Effect of changes in sodium intake and of the addition of hiazide diuretic on the blood pressure lowering effect of nifedipine. f Cardiovasc Pharmacol 1987;10(suppl 10):57-60.

9 MacGregor GA, Cappuccio FP, Markandu ND. Sodium intake, high blood pressure and calcium channel blockers. Am $\mathcal{F}$ Med 1987;82 (suppl 3B):16-22.

20 Cappuccio FP, Markandu ND, Tucker F, Sagnella GA, MacGregor GA. Does a diuretic cause a further fall in blood pressure in hypertensive patients already on nifedipine? Fournal of Clinical Hypertension 1986;4:346-53.

21 Cappuccio FP, Markandu ND, Tucker F, Shore AC MacGregor GA A double-blind study of the blood pressure lowering effect of a hiazide diuretic in study of the blood pressure lowering effect of a thiazide diuretic in hypertensive $p$

22 Salvett A, Magagna A, Innocenti $\mathrm{P}$, et al. Chlorthalidone does not increase the hypotensive effect of nifedipine in essential hypertensives: a crossover multicentre study. I Hypertens 1989:7 (suppl 6):250-1.

23 Williams SA, Rayman G, Tooke JE. Oedema caused by vasodilator therapy: evidence for impairment of posturally-induced vasoconstriction [Abstract] Int $\mathcal{J}$ Microcirc Clin Exp 1986;5:393.

(Accepted 18 fuly 1990)

\title{
Lipid screening: Is it enough to measure total cholesterol concentration?"
}

\author{
H A WLNeil, DLMant, L Jones, B LMorgan, J ILMann
}

\begin{abstract}
Objectives-To determine whether measurement of total cholesterol concentration is sufficient to identify most patients at lipoprotein mediated risk of coronary heart disease without measurement of triglyceride and high density lipoprotein (HDL) cholesterol concentrations.
\end{abstract}

Design-Cross sectional screening programme.

Setting-Six general practices in Oxfordshire.

Patients-1901 Men and 2068 women aged 25-59.

Main outcome measure-Cardiovascular risk as assessed by fasting venous plasma concentrations of total cholesterol, triglyceride, and HDL cholesterol.

Results -2931 Patients (74\% of those screened) had a total cholesterol concentration of $<6.5 \mathrm{mmol} / 1$. If the triglyceride concentration had not been measured in these patients isolated hypertriglyceridaemia ( $\geqslant 2.3 \mathrm{mmol} / \mathrm{l}$ ) would have remained undetected in 185. Among these 185 patients, however, 123 were overweight or obese and only 18 $(0.6 \%$ of those screened) had an increased risk associated with both a raised triglyceride concentration ( $\geqslant 2.3 \mathrm{mmol} / \mathrm{l}$ ) and a low HDL cholesterol concentration $(<0.9 \mathrm{mmol} / \mathrm{l})$. Conversely, in the 790 patients with predominant hypercholesterolaemia (cholesterol concentration $\geqslant 6.5 \mathrm{mmol} / \mathrm{l}$ and triglyceride concentration $<2.3 \mathrm{mmol} / \mathrm{l}$ ) measurement of HDL cholesterol concentration showed that 348 (9\% of those screened) had only a moderately increased risk with a ratio of total to HDL cholesterol of $<4.5$ and 104 had a low risk with a ratio of $<3.5$.

Conclusions-Fasting triglyceride and HDL cholesterol concentrations identify few patients at increased risk of coronary heart disease if the total cholesterol concentration is less than $6.5 \mathrm{mmol} / 1$. HDL cholesterol and triglyceride concentrations should, however, be measured in patients with a total cholesterol concentration exceeding this value. Total cholesterol concentration alone may overestimate risk in a considerable number of these patients, and measurement of HDL cholesterol concentration allows a more precise estimate of risk. Measurement of the triglyceride concentration is required to characterise the lipoprotein abnormality. A patient should not be started on a drug that lowers lipid concentrations without having had a full lipoprotein assessment including measurement of HDL cholesterol concentration.

University of Otago,

Dunedin, New Zealand

J I Mann, DM, professor of

human nutrition

Correspondence to: Dr Neil.
Hypercholesterolaemia is a major and modifiable risk factor for coronary heart disease. Both dietary and
Introduction drug treatment can reduce morbidity and mortality from cardiovascular disease, ${ }^{1-4}$ and several policy statements have provided practical guidelines for the management of hyperlipidaemias. The most widely adopted guidelines in the United Kingdom are those of the European Atherosclerosis Study Group 5 and the British Hyperlipidaemia Association. ${ }^{6}$ Although these take account of high density lipoprotein (HDL) cholesterol and triglyceride concentrations in making recommendations for treatment, they do not specifically recommend any measurement other than that of total cholesterol concentration for screening.

Various protocols are used in practice; some are restricted to random measurement of cholestero concentration, others include measurement of fasting triglyceride concentrations, and some also include measurement of HDL cholesterol concentrations. These differences reflect the limitations of the available data. The evidence for hypertriglyceridaemia as an independent risk factor for coronary heart disease is much less well established than that for hypercholesterolaemia, ${ }^{78}$ but the Framingham study suggests that the risk of coronary heart disease is increased in people with normal cholesterol concentrations, high triglyceride concentrations, and low HDL cholesterol concentrations. ${ }^{9}$ It is therefore important to know how many patients at high risk might be missed if measurements of HDL cholesterol and triglyceride concentrations were restricted to patients with a total cholesterol concentration exceeding a predetermined value. A concentration of $6.2 \mathrm{mmol} / \mathrm{l}$ is used in the United States, ${ }^{10}$ and $6.5 \mathrm{mmol} / 1$ has been suggested in the United Kingdom. ${ }^{11}$ As prospective studies have shown an inverse relation between plasma concentrations of HDL cholesterol and the incidence of coronary heart disease $^{31213}$ it is also important to know what proportion of patients with raised total cholesterol concentrations can be shown by measurement of the HDL cholesterol concentration to be at little or no excess risk of coronary heart disease.

Our aim was to determine the extent of the misclassification of the risk of coronary heart disease associated with a lipid screening protocol that measures only total cholesterol concentration.

\section{Patients and methods}

Six general practices in Oxfordshire participated in the study, which was part of a larger survey of the distribution of plasma lipid concentrations and prevalence of other risk factors for cardiovascular disease. ${ }^{14}$ Altogether 1912 men and 2094 women aged 25-59 were recruited either opportunistically when 
visiting a surgery or by random selection from age-sex registers of practices. The results of measurement of lipoprotein concentrations were incomplete for 37 patients, who were excluded from the analysis.

Height and weight were measured, and the body mass index (weight $(\mathrm{kg}) /$ height $(\mathrm{m})^{2}$ ) was calculated (except in five patients with missing results). A fasting venous blood specimen was taken without prolonged stasis after patients had been sitting for five minutes; disodium edetate $(2.7 \mathrm{mmol} / \mathrm{l})$ was used as anticoagulant. Plasma concentrations of cholesterol, triglyceride, HDL cholesterol, very low density lipoprotein (VLDL) cholesterol, and glucose were measured, and the low density lipoprotein (LDL) cholesterol concentration was calculated by subtraction.

Cholesterol and triglyceride concentrations were analysed enzymatically by an automated procedure with standard enzyme kits (cholesterol kit 236691, cholesterol oxidase/peroxidase-aminophenazone; triglyceride kit 701904, glycerol phosphate oxidase/peroxidase-aminophenazone; Boehringer, Germany) HDL cholesterol concentration was measured by differential precipitation with heparin

TABLE I-Relation between total cholesterol and triglyceride concentrations in 3969 patients

\begin{tabular}{lcrrrr}
\hline & & \multicolumn{4}{c}{ Triglyceride $(\mathrm{mmol} / \mathrm{l})$} \\
\cline { 3 - 5 } Cholesterol (mmol/ $)$ & No of patients & $<2 \cdot 3$ & $2 \cdot 3-$ & $5 \cdot 7 \cdot$ & $\geqslant 10$ \\
\hline$<5 \cdot 2$ & 1148 & 1117 & 30 & 1 & \\
$5 \cdot 2-$ & 1783 & 1629 & 146 & 8 & 2 \\
$6 \cdot 5-$ & 860 & 680 & 173 & 5 & 3 \\
\hline $7 \cdot 8$ & 178 & 110 & 61 & 4 & 5 \\
\hline Total & 3969 & 3536 & 410 & 18 & 5 \\
\hline
\end{tabular}

TABLE II-Relation between triglyceride and HDL cholesterol concentrations in 2931 patients with total cholesterol concentration less than $6.5 \mathrm{mmol} / \mathrm{l}$

\begin{tabular}{lccccrr}
\hline & \multicolumn{5}{c}{ HDL cholesterol (mmoll) } \\
\cline { 2 - 7 } Triglyceride (mmol/l) & No of patients & $<0 \cdot 9$ & 0.9 & $1 \cdot 0-$ & $1 \cdot 3-$ & $\geqslant 2 \cdot 0$ \\
\hline$<1 \cdot 7$ & 2457 & 34 & 35 & 435 & 1632 & 321 \\
$1 \cdot 7-$ & 289 & 15 & 10 & 101 & 147 & 16 \\
$2 \cdot 3-$ & 176 & 17 & 16 & 72 & 67 & 4 \\
$>5 \cdot 6$ & 9 & 1 & 2 & 4 & & 2 \\
\hline
\end{tabular}

TABLE III-Relation between total cholesterol and HDL cholesterol concentrations in 1586 men and 1950 women with triglyceride concentration less than $2.3 \mathrm{mmol} / \mathrm{l}$

\begin{tabular}{|c|c|c|c|c|c|c|c|c|c|c|}
\hline \multirow{3}{*}{$\begin{array}{l}\text { Total cholesterol } \\
(\mathrm{mmol} / \mathrm{l})\end{array}$} & & & \multicolumn{8}{|c|}{ HDL cholesterol $(\mathrm{mmol} / \mathrm{l})$} \\
\hline & \multicolumn{2}{|c|}{ No of patients } & \multicolumn{2}{|c|}{$<0.9$} & \multicolumn{2}{|c|}{$0.9-$} & \multicolumn{2}{|c|}{ 1.3- } & \multicolumn{2}{|c|}{$\geqslant 2.0$} \\
\hline & Men & Women & Men & Women & Men & Women & Men & Women & Men & Women \\
\hline$<6.5$ & 1213 & 1533 & 33 & 16 & 379 & 202 & 731 & 1048 & 70 & 267 \\
\hline $6.5-$ & 327 & 353 & 11 & 2 & 90 & 41 & 201 & 225 & 25 & 85 \\
\hline$>7.8$ & 46 & 64 & 1 & & 7 & 12 & 30 & 40 & 8 & 12 \\
\hline
\end{tabular}

TABLE IV-Relation between total cholesterol concentration and ratio of total to HDL cholesterol concentrations in 1586 men and 1950 women with triglyceride concentration less than $2 \cdot 3$ mmol/l

\begin{tabular}{|c|c|c|c|c|c|c|c|c|c|c|}
\hline \multirow{3}{*}{$\begin{array}{l}\text { Total cholesterol } \\
(\mathrm{mmol} / \mathrm{l})\end{array}$} & & & \multicolumn{8}{|c|}{ Total: HDL cholesterol } \\
\hline & \multicolumn{2}{|c|}{$<3.5$} & \multicolumn{2}{|c|}{ 3.5- } & \multicolumn{2}{|c|}{$4 \cdot 5-$} & \multicolumn{2}{|c|}{$5 \cdot 5-$} & \multicolumn{2}{|c|}{$\geqslant 6.5$} \\
\hline & Men & Women & Men & Women & Men & Women & Men & Women & Men & Women \\
\hline$<6.5$ & 401 & 972 & 476 & 415 & 241 & 107 & 66 & 27 & 29 & 12 \\
\hline $6.5-$ & 22 & 77 & 86 & 136 & 116 & 90 & 63 & 29 & 40 & 21 \\
\hline$>7 \cdot 8$ & 2 & 3 & 7 & 15 & 10 & 21 & 14 & 11 & 13 & 14 \\
\hline
\end{tabular}

TABLE V-Relation between total cholesterol and LDL cholesterol concentrations in 1586 men and 1950 women with triglyceride concentration less than $2 \cdot 3 \mathrm{mmol} / \mathrm{l}$

\begin{tabular}{|c|c|c|c|c|c|c|c|c|c|c|}
\hline \multirow{3}{*}{$\begin{array}{l}\text { Total cholesterol } \\
(\mathrm{mmol} / \mathrm{l})\end{array}$} & & & \multicolumn{8}{|c|}{ LDL cholesterol $(\mathrm{mmol} / \mathrm{l})$} \\
\hline & \multicolumn{2}{|c|}{$<3.5$} & \multicolumn{2}{|c|}{$3 \cdot 5-$} & \multicolumn{2}{|c|}{$4 \cdot 0-$} & \multicolumn{2}{|c|}{$4 \cdot 5-$} & \multicolumn{2}{|c|}{$\geqslant 5 \cdot 0$} \\
\hline & Men & Women & Men & Women & Men & Women & Men & Women & Men & Women \\
\hline$<6.5$ & 644 & 1047 & 323 & 320 & 207 & 144 & 37 & 21 & 2 & 1 \\
\hline $\begin{array}{r}6.5- \\
>7 \cdot 8\end{array}$ & 2 & 1 & 7 & 27 & 68 & 104 & 127 & $\begin{array}{r}121 \\
2\end{array}$ & $\begin{array}{r}123 \\
46\end{array}$ & $\begin{array}{r}100 \\
62\end{array}$ \\
\hline
\end{tabular}

and $92 \mathrm{mM}$ manganese chloride, ${ }^{15}$ and sodium dodecylsulphate was used to precipitate VLDL (the quality control data for the lipid measurements have been reported previously ${ }^{14}$ ). Plasma glucose concentrations were measured by the glucose oxidase method.

The limits at which action should be taken recommended by the European Atherosclerosis Study Group were used to categorise total cholesterol and triglyceride concentrations and to define the lower limit of HDL cholesterol concentration $(0.9 \mathrm{mmol} / \mathrm{l})$ and the upper limit of LDL cholesterol concentration $(4.0 \mathrm{mmol} / \mathrm{l})$ for risk assessment. ${ }^{5}$ The optimal ratio of total to HDL cholesterol concentration for preventing coronary heart disease was defined as 3.5 with an upper limit of $4 \cdot 5 .^{16}$ Predominant hypercholesterolaemia was defined as a total cholesterol concentration of $\geqslant 6.5 \mathrm{mmol} / \mathrm{l}$ and a triglyceride concentration of $<2 \cdot 3 \mathrm{mmol} / 1$, and isolated hypertriglyceridaemia was defined as a triglyceride concentration of $\geqslant 2.3 \mathrm{mmol} / \mathrm{l}$ and a cholesterol concentration of $<6.5 \mathrm{mmol} / \mathrm{l}$. A simplified classification was used to categorise subjects with a body mass index of 25-29 as overweight and those with a body mass index $\geqslant 30$ as obese. ${ }^{17} \mathrm{~A}$ fasting glucose concentration of $\geqslant 7.8 \mathrm{mmol} / 1$ was used as the diagnostic criterion for inadequately controlled or possible undiagnosed diabetes mellitus. ${ }^{18}$ The association between different categories of total cholesterol and triglycerides with HDL cholesterol, LDL cholesterol, the ratio of total to HDL cholesterol, glucose, and body mass index was analysed by cross tabulation with the statistical package SPSSX. ${ }^{19}$ The approximate $95 \%$ confidence intervals were calculated for estimates of prevalence ${ }^{20}$ where appropriate, and when the numbers were less than 20 confidence intervals were obtained by assuming a Poisson distribution. ${ }^{21}$ The $\chi^{2}$ test or Fisher's exact test was used to test for differences between groups. A two tailed level of significance of $\mathrm{p}<0.05$ was considered to be significant.

\section{Results}

The mean total cholesterol concentration by age and sex has been reported. ${ }^{14}$ Table I shows the relation between total cholesterol and triglyceride concentrations. It shows that by restricting measurement of triglyceride concentration to patients with a total cholesterol concentration of $\geqslant 6.5 \mathrm{mmol} / \mathrm{l}$ isolated hypertriglyceridaemia of $\geqslant 2.3 \mathrm{mmol} / 1$ would remain undetected in 185 patients in the screened population $(4 \cdot 7 \%, 95 \%$ confidence interval $4.0 \%$ to $5 \cdot 4 \%), 176$ of whom had a triglyceride concentration of $2 \cdot 3$ $5.6 \mathrm{mmol} / \mathrm{l}$. The body mass index was calculated for 180 of these patients with isolated hypertriglyceridaemia (results were missing for five patients); 83 were overweight (body mass index 25-29) and 40 were obese (body mass index $\geqslant 30$ ). A fasting glucose concentration $\geqslant 7.8 \mathrm{mmol} / \mathrm{l}$ was found in four $(0.9 \%)$ patients with isolated hypertriglyceridaemia compared with seven $(0 \cdot 2 \%)$ with a triglyceride concentration of $<2.3 \mathrm{mmol} / \mathrm{l}(\mathrm{p}=0.003$, Fisher's exact test).

Table II shows the effect of excluding measurement of triglyceride and HDL cholesterol concentrations from the screening protocol. A raised triglyceride $(\geqslant 2.3 \mathrm{mmol} / \mathrm{l})$ and a low $\mathrm{HDL}$ cholesterol $(<0.9$ $\mathrm{mmol} / \mathrm{l}$ ) concentration was found in only 18 patients $(0.6 \%$ of the screened population, $95 \%$ confidence interval $0.4 \%$ to $1.0 \%$ ) with a total cholesterol concentration $<6.5 \mathrm{mmol} / \mathrm{l}$. Among the 1038 patients with a total cholesterol concentration $\geqslant 6.5 \mathrm{mmol} / 1$ (data not shown) $12(1 \%)$ had a raised triglyceride concentration $(\geqslant 2.3 \mathrm{mmol} / \mathrm{l})$ and a low HDL cholesterol concentration $(<0.9 \mathrm{mmol} / \mathrm{l})$.

Tables III-V show how by measuring HDL cholesterol concentration and calculating both LDL cholesterol and the ratio of total to HDL cholesterol 
concentrations it is possible to identify patients at lower cardiovascular risk than would be suggested by the total cholesterol concentration alone. ${ }^{1622}$ The tables are restricted to the 1586 men and 1950 women with triglyceride concentrations $<2 \cdot 3 \mathrm{mmol} / 1$. Table III shows that women had higher HDL cholesterol concentrations than men and that, of the 790 patients with predominant hypercholesterolaemia (total cholesterol concentration $\geqslant 6.5 \mathrm{mmol} / \mathrm{l}), 130(16 \%$, $95 \%$ confidence interval $14 \%$ to $19 \%$ ) had an HDL cholesterol concentration $\geqslant 2.0 \mathrm{mmol} / \mathrm{l}(23 \%$ women $v$ $9 \%$ men; difference $14 \%, 9 \%$ to $19 \%$ ). Table IV shows that, of the 790 patients with predominant hypercholesterolaemia, $348(44 \%, 41 \%$ to $47 \%)$ had a ratio of total to HDL cholesterol $<4.5$ and $104(13 \%, 11 \%$ to $16 \%$ ) had a ratio of $<3 \cdot 5$. Table $V$ shows that 209 of the patients with predominant hypercholesterolaemia $(26 \%, 23 \%$ to $30 \%)$ had an LDL cholesterol concentration $<4.5 \mathrm{mmol} / \mathrm{l}$ and $37(5 \%, 3 \%$ to $6 \%)$ had a concentration $<4.0 \mathrm{mmol} / \mathrm{l} ; 108$ patients had a total cholesterol concentration $>7.8 \mathrm{mmol} / \mathrm{l}$ and an LDL cholesterol concentration $>5.0 \mathrm{mmol} / \mathrm{l}$ (table $\mathrm{V}$ ), of whom 25 had a ratio of total to HDL cholesterol $<4.5$ and four a ratio $<3.5$.

\section{Discussion}

Our results have several implications for lipid screening. Restricting screening to the measurement of total cholesterol concentration probably does not result in a serious underestimate of the risk of coronary heart disease in the population. Although isolated hypertriglyceridaemia would go undetected in nearly $5 \%$ of the population, none of these patients in our population had concentrations sufficiently raised to be associated with an increased risk of pancreatitis. Most affected patients had mild hypertriglyceridaemia and drug treatment would not be indicated as the evidence that hypertriglyceridaemia is an independent risk factor for coronary heart disease remains inconclusive..$^{7823}$ Hypertriglyceridaemia is often secondary to obesity, alcohol abuse, impaired glucose tolerance, or diabetes, and we found that about two thirds of patients with isolated hypertriglyceridaemia were either overweight or obese. Although measurement of triglyceride concentrations may be required as part of the management of underlying conditions such as diabetes, treatment for these conditions is usually required irrespective of lipid abnormalities.

Fasting triglyceride concentrations can most usefully be measured selectively in patients with raised total cholesterol concentrations. Because of the wide variability in lipid concentrations from day to day in individual people ${ }^{24}$ the diagnosis of hypercholesterolaemia should be based on at least two separate measurements, and a repeat measurement to confirm the diagnosis can conveniently include measurement of fasting triglyceride concentrations. Among patients with total cholesterol concentrations $\geqslant 6.5 \mathrm{mmol} / \mathrm{l}$ in our study about a quarter had triglyceride concentrations exceeding $2 \cdot 3 \mathrm{mmol} / \mathrm{l}$. In these patients measurement of the triglyceride concentration is needed to identify the lipoprotein abnormality present-in particular, remnant and familial combined hyperlipidaemia, which are strongly associated with coronary heart disease-and to determine the treatment.

A screening protocol that excludes measurement of triglycerides and HDL cholesterol concentrations cannot, of course, identify people with normal cholesterol, high triglyceride, and low HDL cholesterol concentrations. The Framingham study suggests that this particular lipoprotein profile is associated with an increased risk of coronary heart disease. Affected patients are usually overweight, often have raised serum uric acid concentrations, and have about a twofold excess risk of developing diabetes. ${ }^{9}$ They might also be expected to be insulin resistant, hyperinsulaemic, and often hypertensive as well as glucose intolerant ${ }^{2526}$; these multiple metabolic abnormalities have been variously termed syndrome X or Reaven's syndrome. ${ }^{27}$ Using the same diagnostic criteria as were used in the Framingham study (HDL cholesterol concentration $<1.0 \mathrm{mmol} / 1$ and triglyceride concentration $\geqslant 1.7 \mathrm{mmol} / \mathrm{l}$ ), we found that the prevalence of this condition among patients with a total cholesterol concentration $<6.5 \mathrm{mmol} / \mathrm{l}$ was only $2 \%(61 / 2931)$, which suggests that lipid screening should be restricted initially to measurement of total cholesterol concentration.

Prospective studies have shown an inverse relation, which is stronger in women than men, ${ }^{28}$ between plasma concentrations of HDL cholesterol and the incidence of coronary heart disease. ${ }^{31011}$ It is important, therefore, to identify which patients have raised total and HDL cholesterol concentrations and are at little or no excess risk of coronary heart disease. As expected, our results confirmed that HDL cholesterol concentrations were significantly higher in women. Almost a quarter of women with normal triglyceride and raised total cholesterol concentrations of $6 \cdot 5-7 \cdot 8 \mathrm{mmol} / \mathrm{l}$ had a ratio of total to $\mathrm{HDL}$ cholesterol or an $\mathrm{LDL}$ cholesterol concentration that is not associated with an excess risk of coronary heart disease. Current guidelines recommend that treatment with drugs that lower lipid concentrations should be considered for patients with predominant hypercholesterolaemia with a total cholesterol concentration of more than $7.8 \mathrm{mmol} / \mathrm{l}^{.56}$ We found that about $5 \%$ of such patients had a ratio of total to HDL cholesterol that may not be sufficiently raised to justify prescribing potentitally lifelong drug treatment in the absence of other risk factors.

The guidelines for lipid screening derived from our study are consistent with existing recommendations for the management of hyperlipidaemia in adults ${ }^{56}$ and are applicable to populations of a similar age identified opportunistically or by random screening in genera practice but not to patients with conditions such as diabetes that are associated with dyslipidaemias. Screening should initially be restricted to measurement of non-fasting total cholesterol concentration. If the total cholesterol concentration is $\geqslant 6.5 \mathrm{mmol} / \mathrm{l}$ the fasting triglyceride concentration should be measured to characterise the lipoprotein abnormality present and to determine treatment. Measurement of HDL cholesterol concentration in patients with a raised total cholesterol concentration is important because high concentrations allow those at little excess risk of coronary heart disease to be identified whereas reduced concentrations, often in association with hypertriglyceridaemia, provide a more precise measure of risk. A patient should not be started on a drug that lowers lipid concentrations without having had a full lipoprotein assessment including measurement of $\mathrm{HDL}$ cholesterol concentration.

We thank Dr M F Laker for commenting on the manuscript and the general practitioners-Drs G E Sacks, M L Bowen, C Sherlock, A D Cole, P G Kay, and L Grainger-and their partners who participated in the study.

1 Frick $\mathrm{MH}$, Elo $\mathrm{O}$, Haapa $\mathrm{K}$. Helsinki heart study: primary prevention tria with gemfibrozil in middle-aged men with dyslipidemia. $N$ Engl $\mathcal{F}$ Med with gemfibrozil in

2 Lipid Research Clinics. Coronary primary prevention trial results. JAMA 1984;251:351-64.

3 Hjermann I, Byre KV, Holme I, Leren P. Effect of diet and smoking on the incidence of coronary heart disease. Lancet 1981;ii:1303-10.

4 Peto R, Yusuf S, Collins R. Cholesterol-lowering trial results in their epidemiological context. Circulation 1985;75(suppl 2):451.

5 Study Group, European Atherosclerosis Society. The recognition and management of hyperlipidaemia in adults: a policy statement of the European Atherosclerosis Society. Eur Heart f 1988;9:571-600.

6 Shepherd J, Betteridge DJ, Durrington P, et al. Strategies for reducing coronary heart disease and desirable limits for blood lipid concentrations: 
guidelines of the British Hyperlipidaemia Association. Br Med F 1987;295: 1245-6.

7 Austin AA. Plasma triglyceride as a risk factor for coronary heart disease. $A m \mathcal{F}$ Epidemiol 1989;129:249-59.

8 Hulley SH, Rosenman RH, Bawol RD, Brand RJ. Epidemiology as a guide to clinical decisions. $N$ Engl f Med 1980;25:1383-9.

9 Castelli WP. The triglyceride issue: a view from Framingham. Am Heart $f$ 1986;112:432-7.

10 National Education Program Expert Panel. Report of the national cholesterol education program expert panel on detection and treatment of high blood cholesterol in adults. Arch Intern Med 1988;148:36-69.

11 Lewis B, Assmann G, Mancini M, Stein Y, eds. Handbook of coronary hear disease prevention. London: Current Medical Literature, 1989.

12 Gordon T, Kannel WB, Castelli WP, Dawber TR. Lipoproteins, cardiovascular disease, and death. The Framingham study. Arch Intern Med 1981;141:1123-31.

13 Pocock SJ, Shaper AG, Phillips AN. Concentrations of high density lipoprotein cholesterol, triglycerides, and total cholesterol in ischaemic heart disease. BrMed f 1989;298:998-1002.

14 Mann JI, Lewis B, Shepherd J, et al. Blood lipid concentrations and other cardiovascular risk factors: distribution, prevalence, and detection in Britain. Br Med f 1988;296:1702-6.

15 Burstein M, Scholnick HR, Morfin R. Rapid method for the isolation of lipoproteins from human serum by precipitation with polyanions. $\mathcal{F}$ Lipid Res 1970;11:583-95

16 Castelli WP. Reversing the course of atherosclerosis-a view from Framingham. Kalamazoo, Michigan: Upiohn, 1989.
17 Royal College of Physicians. Obesity. $\mathcal{f} R$ Coll Physicians Lond 1983;17:5-65. 18 WHO Study Group. Diabetes mellitus. Geneva: World Health Organisation, 1985.

19 Anonymous. SPSSX user's guide. 3rd ed. New York: McGraw-Hill, 1988.

20 Wilson EB. Probable inference. The law of succession and inference. Fournal of the American Statistical Association 1927;22:209-12.

21 Lenter C, ed. Geigy scientific tables 2. Basel: Ciba-Geigy, 1982.

22 Assman G, Schulte H. Procam trial. Zurich: Panscientia Verlag, 1986.

23 National Heart, Lung, and Blood Institute Consensus Development Panel. Treatment of hypertriglyceridemia. FAMA 1984;251:1196-200.

24 Jacobs DR, Barrett-Conor E. Retest reliability of plasma cholesterol and triglycerides. Am J Epidemiol 1982;6:878-8

25 Reaven GM. Role of insulin resistance in human disease. Diabetes 1988;37 $1595-607$

26 Fuh MM-T, Shieh S-M, Wu D-A, Chen YD-I, Reaven GM. Abnormalities of carbohydrate and lipid metabolism in patients with hypertension. Arch Intern Med 1987;147:1035-8.

27 Anonymous. Type 2 diabetes or NIDDM: looking for a better name [Editorial]. Lancet 1989;i:589-91.

28 Jacobs DR, Mevane IL, Bangdiwala SI, Criqui MH, Tyroler HA. High density lipoprotein cholesterol as a predictor of cardiovascular disease mortality in men and women: the follow-up study of the Lipid Research Clinics prevalence study. Am $\mathcal{F}$ Epidemiol 1990;131:32-47.

(Accepted 16 fuly 1990

\title{
Atenolol in essential hypertension during pregnancy
}

\author{
Lucy Butters, Susan Kennedy, Peter C Rubin
}

Abstract
Objective-To determine the effect of atenolol on the outcome of pregnancy in women with essential hypertension.

Design-Prospective, randomised, double blind, placebo controlled study.

Setting-Hospital clinic.

Patients-33 Women with mild essential hypertension (systolic blood pressure $140-170 \mathrm{~mm} \mathrm{Hg}$ or diastolic pressure $90-110 \mathrm{~mm} \mathrm{Hg}$ on two occasions at least 24 hours apart) consecutively referred to two obstetric medical clinics. Four patients in the placebo group were withdrawn from the study: control of blood pressure was inadequate in two, one developed breathlessness, and one changed her mind about participating. The mean gestation in the 29 remaining women on entry to the study was 15.9 weeks.

Main outcome measures-Blood pressure and birth weight.

Intervention-14 Women received placebo. 15 Women received atenolol $50 \mathrm{mg}$ daily initially, increasing until either the blood pressure was $<140 / 90 \mathrm{~mm} \mathrm{Hg}$ or a dose of $200 \mu \mathrm{g}$ daily was reached.

Results - The mean blood pressure on entry was $148 / 86 \mathrm{~mm} \mathrm{Hg}$ in the group given atenolol and 144/86 $\mathrm{mm} \mathrm{Hg}$ in the group given placebo. During treatment the mean diastolic pressure was significantly reduced by atenolol compared with placebo (to $74 v 81 \mathrm{~mm}$ $\mathrm{Hg}$; difference in means ( $95 \%$ confidence interval) $7.0(2.9$ to 10.0$) \mathrm{mm} \mathrm{Hg})$ but the effect on systolic pressure was marginal (132 $v 136 \mathrm{~mm} \mathrm{Hg} ; 4.0(-1.4$ to 8.6) $\mathrm{mm} \mathrm{Hg}$ ). Babies in the atenolol group had a significantly lower birth weight than those in the placebo group ( $2620 \mathrm{~g} v 3530 \mathrm{~g} ; 910$ (440 to 1380 ) g).

Conclusion-Atenolol given from the end of the first trimester in patients with mild hypertension is associated with intrauterine growth retardation. When taken in conjunction with the results of a previous study in which methyldopa was given these findings indicate that benefit is unlikely to result from treating mild essential hypertension in pregnancy.

\section{Introduction}

The value of antihypertensive drugs in managing mild to moderate essential hypertension during pregnancy is unclear. A study by Redman et al in the 1970s found that the outcome of pregnancy was better in a group who received methyldopa than in a group who did not receive any treatment. ${ }^{1}$ It was difficult, however, to ascribe the better outcome to the reduction in blood pressure, and Redman et al concluded that perhaps an unidentified pharmacological effect of methyldopa was responsible.

Extrapolating from this hypothesis, we argued that if it was a reduction in blood pressure that was responsible for the better outcome then a different antihypertensive agent would have the same beneficial effect. We showed that atenolol given to women who develop hypertension in the third trimester successfully lowers blood pressure and usefully prolongs pregnancy, with a consequent reduction in perinatal morbidity. ${ }^{2}$ In the present study we assessed the value of atenolol in women whose pregnancies were complicated by essential hypertension.

\section{Patients and methods}

The randomised, placebo controlled, double blind study was approved by the research and ethical committee of Greater Glasgow Health Board Northern District. Thirty three women who were consecutively referred to the obstetric medical clinics at Stobhill General Hospital and the Queen Mother's Hospital for management of essential hypertension were studied. The criteria for entry to the study were either a systolic blood pressure between 140 and $170 \mathrm{~mm} \mathrm{Hg}$ or a diastolic blood pressure (Korotkoff phase $\mathrm{V}$ ) between 90 and $110 \mathrm{~mm} \mathrm{Hg}$ on two occasions separated by at least 24 hours. Recruitment took place at between 12 and 24 weeks' gestation. Women were excluded from the study if they had any of the usual contraindications to use of a $\beta$ blocker.

For those women who received active treatment the starting dose of atenolol was $50 \mathrm{mg}$ daily and the number of tablets was increased at each visit until either the blood pressure was $<140 / 90 \mathrm{~mm} \mathrm{Hg}$ or a dose of $200 \mathrm{mg}$ daily was reached. The patients were seen at intervals of four weeks until they were 28 weeks pregnant, then every two weeks until they were 36 weeks pregnant, and then weekly until delivery. Babies were assessed at birth and at 12 months of age.

Data were analysed by $t$ test. In the case of blood 